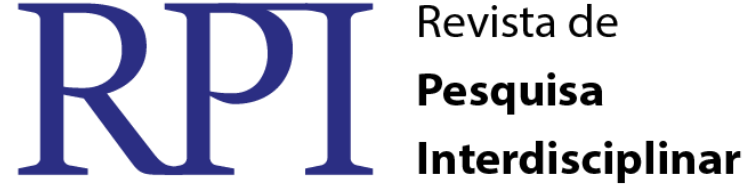

\section{EXPERIMENTOS DE FÍSICA: RENOVANDO A PRÁTICA DOCENTE COM MATERIAIS DE BAIXO CUSTO.}

\author{
Magna Abrantes de Oliveira - CFP/UFCG \\ Anderson A. Lima - CFP/UFCG
}

\begin{abstract}
Resumo
É fato que a dificuldade de aprendizagem que os alunos apresentam em relação aos estudos de Física, principalmente no nível médio, vem tornando-se um agravante para o desenvolvimento na área da pesquisa científica. Podem-se destacar vários fatores por partes dos/das alunos/as que demonstrem falta de interesse pelo Componente Curricular de Física. Muitos consideram a Física como um Componente Curricular difícil, por isso que são necessários novos métodos de ensino para motivar a participação do/a aluno/a e assim aumentar o interesse dos mesmos pelas aulas. Para possibilitar a aprendizagem significativa, o/a professor/a precisa deixar um pouco a teoria de lado e dar ênfase para as aulas práticas. Através da experimentação, pode-se dar aos/as alunos/as a motivação necessária para aprenderem Física, despertando a curiosidade dos mesmos a respeito dos conhecimentos científicos relacionados a este Componente Curricular. Surge-se, então, a necessidade de trabalhar com experimentos para observar as contribuições da realização do projeto numa escola pertencente à rede publica de ensino do estado da Paraíba, localizada no município de Vieirópolis. Este projeto contempla apenas o Ensino Médio, no período de julho a outubro de 2015, com alunos do $1^{\circ}$ ano "A" e "B". O principal objetivo deste projeto foi examinar as contribuições da utilização de aulas experimentais no Componente Curricular de Física para o processo ensino aprendizagem. Trabalhar com alunos, principalmente numa área que se tem maior dificuldade de aprender, implica realizar uma mudança na prática docente, a fim de obter melhor resultados por parte desses alunos, no qual foi observado o interesse e a participação dos mesmos nas aulas de Física e que a realização desses experimentos de Física proporcionaram aos alunos uma maior participação nas aulas e um melhor desempenho em sua aprendizagem.
\end{abstract}

Palavras-Chave: Ensino aprendizagem; prática docente; experimentos de Física.

\section{PHYSICS EXPERIMENTS: RENEWING THE TEACHING PRACTICE WITH LOW COST MATERIALS.}

\begin{abstract}
It is a fact that the learning difficulties that students have in relation to studies of physics, especially at the secondary level, is becoming an aggravating factor for the development in scientific research. They can highlight several factors for parts of the students demonstrating the lack of interest in Curriculum Component Physics. Many consider physics as a curricular component difficult, why are needed new teaching methods to motivate the participation of the student and thus increase the interest of the same classes. To enable meaningful learning, the teacher the need to leave a little aside the theory and give emphasis on the practical classes. Through experimentation, you can give the students the motivation necessary to learn physics, arousing the curiosity of the same about the scientific knowledge related to this curricular component. Comes up, then, the need to work with experiments to observe the contributions of the realization of the project in a school belonging to the network of public education in the state of Paraiba, in the municipality of Vieirópolis. This project includes only
\end{abstract}


high school in the period from July to October 2015, with 1st year students "A" and " B " . The main objective of this project was to examine the contributions of the use of experimental classes in the Course of Physical Component for the learning process. Working with students, especially in an area that is more difficult to learn, involves performing a change in teaching practice in order to get better results by these students, which was observed interest and their participation in Physical and the realization of these physics experiments gave students a greater class participation and improved performance in their learning.

Keywords: Teaching and learning; teaching practice; Physics experiments.

\section{INTRODUÇÃO}

O fato dos/as alunos/as estarem demonstrando falta de estímulo em aprender os conhecimentos básicos da Física vem causando preocupação na comunidade científica e reclamações de muitos professores. O desestímulo desses alunos/as é causado muitas vezes pela falta de inovação dos/as professores/as, pois para muitos professores/as as aulas de Física se limitam apenas à resolução de exercícios.

Segundo Skinner a aprendizagem ocorre devido ao reforço, à repetição, dessa forma o ensino deveria criar condições para que as respostas fossem dadas inúmeras vezes. Ao professor cabia à tarefa de proporcionar tais mecanismos de reforço, criando situações de repetição tantas vezes quantas fossem necessárias até que o/a aluno/a exibisse o comportamento desejado (MOREIRA, 1999). Mesmo ultrapassadas, as ideias de Skinner ainda predominam nos tempos de hoje, podendo ser identificadas nas apostilas e livros didáticos de Física, que apresentam um modelo de exercício resolvido e a seguir uma lista de exercício, favorecendo a aprendizagem por repetição, por reforço. Conforme Zanon e Silva 2000:

As atividades práticas podem assumir papel fundamental na promoção de aprendizagens significativas em ciências e, por isso, consideramos importante valorizar propostas alternativas de ensino que demonstrem potencialidade da experimentação através de inter-relações entre os saberes teóricos e práticos inerentes aos processos do conhecimento escolar. (p.182)

Se os professores tivessem a preocupação de inovar seus procedimentos metodológicos com certeza a Física era vista pelos/as alunos/as com outros olhos. É aí que entraria a utilização de experimentos, quando o/a aluno/a interagir com os experimentos, isso

RPI Revista de Pesquisa Interdisciplinar, Cajazeiras, v. 1, Ed. Especial, 259 - 264, set/dez. de 2016. 
possibilitará uma aprendizagem profunda. Esse contato pode ajudar o/a aluno/a a identificar os conceitos, os fenômenos e as relações com o seu cotidiano, podendo até encontrar algo novo e facilitar ao/à aluno/a aprender, de fato, a Física. A importância das atividades experimentais para o ensino de Física foi também valorizado por Borges (2002):

Por considerar que se trata de um método de aprendizagem que permita a mobilização do aprendiz, no lugar da passividade. Acredita que a riqueza das atividades experimentais consiste em proporcionar aos estudantes $\mathrm{o}$ manuseio de coisas e objetos num exercício de simbolização ou representação, para se atingir a conexão dos símbolos. (p.241-313)

Quando se tem em mãos experimentos que contribuam significativamente para sua aula, tanto com materiais requintados ou de baixo custo, fica mais fácil de explicar os conteúdos para os/a alunos/as, não havendo necessidade exclusivamente do laboratório, podendo ser demonstrado em qualquer ambiente que permita a realização desses, não levando em conta as dificuldades encontradas nas escolas em relação ao uso de laboratório, pois se levada em conta, esse instrumento didático não será possível à realização dele, pois a maioria das escolas não possui laboratório de Física. Para Ribeiro (1955):

\footnotetext{
Aparelhos e montagens improvisadas, executadas com recursos mais modestos laboratórios, deve ser considerada não como solução de emergência, mas ao contrário, como uma técnica desejável para desenvolver as capacidades construtivas e inventidas do estudante.(p.54).
}

Uma boa ferramenta que o/a professor/a pode aderir nas suas aulas é o experimento simples, de baixo custo, que pode ser montado pelos/as alunos/as, pois são materiais simples que qualquer aluno/a pode ter acesso, favorecendo o interesse de participar das aulas de Física, proporcionando a aprendizagem e a participação, onde pode ser conceituados e relacionados com o cotidiano do/a aluno/a. Para relacionar com o seu cotidiano o experimento deve ser executado e transmitido com clareza tanto pelo professor/a quanto pelos/as alunos/as. De nada adianta realizar atividades práticas em aula se as mesmas não propiciam o momento da discussão teórico-prática.

\section{Desenvolvimento}

RPI Revista de Pesquisa Interdisciplinar, Cajazeiras, v. 1, Ed. Especial, 259 - 264, set/dez. de 2016. 
A maioria das escolas não dispõem de laboratórios, materiais e espaços físicos adequados para a realização de experimentação e isso tem dificultado o trabalho dos/das professores/as, mesmo as escolas que dispõem de laboratórios e equipamentos muitas vezes não os utilizam, por razões diversas, tais como a falta de tempo do/a professor/a para o planejamento e a execução das atividades. A experimentação, principalmente quando realizada com materiais de fácil manipulação, facilita o aprendizado e o interesse de conhecer mais sobre a Física. Por isso é necessário que o/a professor/a introduza experimentos nas aulas de Física, tanto experimentos complexos quanto simples, e principalmente, os mais simples, ou seja, aqueles realizados com materiais de baixo custo, pois os/as alunos/as podem ter acesso e até fazerem os experimentos sozinhos, o importante é que as aulas sempre tenha alguma demonstração que contribua significativamente para a aprendizagem do/a aluno/a.

Com esse intuito que se foi trabalhado com o Projeto Experimentos de Física: Renovando a Prática Docente com Materiais de Baixo Custo para observar as contribuições das aulas experimentais nas aulas de Física desenvolvido na Escola Estadual, localizada no auto sertão paraibano mais precisamente na cidade de Vieirópolis. O projeto propõe-se mostrar as contribuições da utilização de aulas experimentais no Componente Curricular de Física para o processo ensino aprendizagem, mediado das realizações de experimentos. Para isso buscou-se trabalhar com as turmas do $1^{\circ}$ ano do ensino médio (turma "A" e "B").

O PROJETO iniciou suas ações no período de julho a outubro de 2015, com alunos do $1^{\circ}$ ano "A" e "B" do ensino médio. Nas quais foram trabalhados experimentos sobre os seguintes assuntos estudados durante o $3^{\circ}$ bimestre (As Leis de Newton e Gravitação Universal). Antes das ações do projeto foram ministrados os conteúdos já citados. Foi realizado a apresentação do projeto iniciando com explanação dos objetivos e em seguida foi organizada dupla para divisão dos conteúdos, através de sorteios dos experimentos selecionados no youtube, orientações de como realizar os experimentos e demonstrações de alguns experimentos através de vídeo do youtube.

Sorteios dos seguintes experimentos:

$\checkmark$ Primeira lei de Newton princípio da inércia;

$\checkmark$ Segunda lei de Newton;

$\checkmark$ O globo voador;

$\checkmark$ Terceira lei de Newton;

$\checkmark$ Carro a jato;

RPI Revista de Pesquisa Interdisciplinar, Cajazeiras, v. 1, Ed. Especial, 259 - 264, set/dez. de 2016. 
$\checkmark$ Experiência da segunda lei de Newton divertida;

$\checkmark$ Experiência de Física ação e reação CSA 2010;

$\checkmark$ Maquete do sistema solar;

$\checkmark$ Ação e reação (Terceira lei);

$\checkmark$ Sistema solar giratório;

$\checkmark$ Mágica do vácuo da vela (Primeira lei).

Logo após o planejamento dos alunos com orientações, foram construídos roteiros, em seguida digitados e testes dos experimentos em sala de aula. Os alunos realizaram os experimentos em sala de aula, explicando como fizeram, os materiais utilizados, o conteúdo abordado e a explicação do experimento, dando a oportunidades aos demais colegas de sala realizarem também o experimento, e por último foram entregues os roteiros. A exposição foi realizada no dia 13 (treze) de outubro de 2015 na FEICICULT - Feira de Ciências e Cultura a partir da 08h00min no espaço da escola onde foi desenvolvido o projeto. Em seguida os visitantes se dirigiam as mesas onde estavam os experimentos, no qual os alunos realizavam os experimentos e explicava como acontecia o fenômeno observado dando a oportunidade aos visitantes realizarem os experimentos.

O projeto promoveu trocas de conhecimento com outras disciplinas, na disciplina de português, foi estimulando a construção de roteiros para facilitar a realização dos experimentos e na disciplina de artes, com a ajuda do professor de artes foi trabalhado com desenhos do sistema solar, para proporcionar aos alunos conhecerem melhor o sistema solar e cada planeta.

Com esse projeto, foi observado o interesse e a participação dos alunos nas aulas de Física, a participação e o contentamento com os experimentos de Física, proporcionarão aos alunos uma maior participação nas aulas, me surpreendendo, minhas expectativas foram superadas, alunos que não participava das aulas, foi uns dos mais que participaram, esforço e dedicado presentes, realizando todas as ações do projeto com muita satisfação, na qual realizarão os experimentos e observaram os seus colegas realizando. $\mathrm{O}$ aproveitamento do projeto não foi $100 \%$, alguns alunos não apresentaram os experimentos, sendo a minoria. $\mathrm{O}$ esperado era que todos participassem, infelizmente não participaram. Mesmo não realizando o experimento, participaram como ouvintes e tiveram a oportunidade de aumenta o seu conhecimento sobre os assuntos estudados.

RPI Revista de Pesquisa Interdisciplinar, Cajazeiras, v. 1, Ed. Especial, 259 - 264, set/dez. de 2016. 


\section{Conclusão}

A elaboração desse projeto foi de suma importância para proporcionar um melhor desempenho na aprendizagem dos/as alunos/as no Componente Curricular de Física. Mostrando a importância da utilização dos experimentos nas aulas para que os/as alunos/as compreendessem mais sobre a Física, principalmente no seu dia a dia. O trabalho experimental é um importante recurso didático, que deve ser utilizado mais vezes pelos/as professores/as, podendo ser feito uma relação da teoria com a prática, havendo sempre uma ligação que ajude na aprendizagem do/a aluno/a.

\section{REFERÊNCIAS}

BORGES, A.T. Novos rumos para o laboratório escolar de ciências. Caderno Brasileiro de Ensino de Física, v. 19, n. 3, p. 291-313, 2002.

MOREIRA, Marco Antonio (1983): Uma abordagem cognitivista ao ensino da Física, a teoria de David Ausubel como sistema de referência para a organização do ensino de ciências. Porto Alegre, Ed. Da Universidade, UFRGS.

RIBEIRO, J. C. O ensino experimental da Física no curso secundário, II Curso de aperfeiçoamento para professores de Física do ensino secundário. Atas do encontro, p.: 49-56. IBECC. MEC-ITA. São Paulo, 1955.

ZANON, Lenir B., SILVA, Lenice H. A experimentação no ensino de Ciências. In: SCHNETZLER, Roseli P., ARAGÃO, Rosália M. R. Ensino de Ciências : fundamentos e abordagens. Campinas: Vieira Gráfica e Editora Ltda. 2000, p.182. 